\title{
O Arco de Maguerez como estruturador pedagógico das TDIC
}

Aline Bairros Soares - PPGEPT/UFSM - aline.qmc.bs@gmail.com Leila Maria Araújo Santos - PPGEPT/UFSM - leilamas@ctism.br Claudia Smaniotto Barin - PPGEPT/UFSM - claudiabarin@nte.ufsm.br

Resumo. Este trabalho é o resultado da investigação sobre o uso do Arco de Maguerez como estruturador pedagógico das tecnologias digitais da informação e da comunicação em sala de aula. O público alvo foi constituído de 25 alunos matriculados na disciplina de Tecnologias de Informação e Comunicação aplicadas na Educação de uma universidade pública federal. A pesquisa suscitou ampliar a compreensão quanto ao potencial pedagógico do Arco de Maguerez, pois ao requerer a observação da realidade e os pontos chave, dá-se foco as necessidades dos envolvidos no processo. A teorização e o sondagem das hipóteses de solução, permitem antecipar situações problema e propiciam uma aplicação organizada e objetiva. Apoiados nos resultados obtidos podemos afirmar que a metodologia utilizada potencializa a performance docente.

Palavras - chave: Arco de Maguerez, Tecnologias Digitais da Informação e da Comunicação. Estruturador pedagógico.

\section{The Maguerez Arch as pedagogical designer of the DICT}

Abstract.This study is the result of the research on the Arch of Maguerez use as pedagogical structurer of the digital information and communication technologies in the classroom. The target audience consisted of 25 students enrolled in the discipline of Information and Communication Technologies applied in Education in Federal University. The research has raised the understanding of pedagogical potential about this methodology, due to require the reality observation and the key points it focuses on needs of those involved in the process. The theorization and the probing of the solution hypotheses allow to anticipate problem situations and provide an organized and objective application. Thus, we can affirm that the methodology used increases teacher performance.

Keywords - chave: Arch of Maguerez, Digital Information and Communication Technologies, Pedagogical designer.

\section{Introdução}

Diante do contínuo avanço tecnológico as tecnologias digitais estão amplamente integradas em nosso cotidiano, provendo fácil permissão a comunicação e informação acessível na web. Em decorrer disso, as Tecnologias Digitais de Informação e Comunicação (TDIC) têm fomentado em todos níveis de ensino a possibilidade de desenvolver projetos em rede que ampliam a construção do conhecimento. Trata-se de uma realidade constante, e que deve, segundo Sancho e Hernández (2006), ser o terreno da educação.

É comum observarmos trabalhos de professores que utilizam os diferentes recursos das TDIC, seja em atividades de resolução de problemas, apresentação ou compartilhamento de conteúdo. No entanto, é necessário ter um planejamento pedagógico para que a incorporação das tecnologias digitais à prática docente tenha suas finalidades alcançadas, pois apenas inseri-las em sala de aula, sem uma reflexão da intenção, não garantem o sucesso da aprendizagem, pois apenas reforça uma prática corrente, como afirma Coll (2009). 
As TDIC requerem que os professores assumam um novo papel reconfigurando as práticas docentes. Assim, é importante que os docentes tenham ciência de qual o momento adequado para o uso das tecnologias digitais em tarefas que permeiam o contexto educacional como, o de gestão, trabalho para salas de aula, aquisição de conhecimento de conteúdo específico e pedagógico, para assim, fundamentar seu desenvolvimento profissional.

Nesse sentido, segundo Kenski (2012) e Moran, Masetto, Behrens (2013), para que o docente assuma essa nova postura frente ao uso pedagógico das TDIC, faz-se necessário uma formação para à aquisição da fluência pedagógica e tecnológica, que permitam a eles se sentirem seguros para usar as tecnologias juntamente com diferentes metodologias educacionais, que venham a contribuir no seu planejamento.

Compreendemos que o processo de ensino pode enriquecer quando há uma reflexão sobre o uso de determinada tecnologia para uma aula. A maneira que o docente utilizará determinado recurso didático digital pode ser potencializado quando integrado a uma metodologia que beneficie o olhar atento aos momentos da aula. Nesse sentido, há na literatura muitos modelos pedagógicos, que são metodologias educacionais com a intenção de contribuir na implementação de projetos, aulas, oficinas, seminários, entre outros (SOARES, 2017).

Nesse cenário, as Metodologias Ativas, vêm despontando no contexto educacional e podem ser maiores aliadas para promoção da aprendizagem, onde o aluno atua como protagonista central, ou seja, coparticipante pelo seu percurso educacional e o professor encontra-se como um facilitador ao processo de ensino (MORAN, 2015).

Fazer o uso da Metodologia Ativa é um estímulo aos educadores, para que exerçam uma práxis dinâmica. Sua utilização provoca a compreensão dos diferentes modos de operacionalização, mas fundamentalmente os princípios pedagógicos que a sustentam, ou seja, os princípios da pedagogia crítica. Dentre as metodologias ativas, destacamos dois modos fundamentais para sua operacionalização: a Problematização e Aprendizagem Baseada em Problemas (BERBEL, 2012).

A metodologia da Problematização é usada em momentos nas quais os temas estejam imbricados com a vida em sociedade, tendo como referência o Arco de Charles Maguerez, exposto pela primeira vez por Bordenave e Pereira, em 1982. Trata-se de um caminho metodológico eficaz que orienta a prática pedagógica do educador e ou pesquisador.

Aprendizagem Baseada em Problemas, se preparam situações, ou seja, temas de estudo que o aluno deverá saber e dominar, sendo determinados previamente quais conhecimentos o aluno deverá possuir para cada uma delas. Cada tema é transformado em um problema para ser discutido em grupo (BERBEL, 1998).

Neste trabalho damos enfoque à problematização por meio do Arco de Maguerez como estruturador da práxis docente para o uso pedagógico das TDIC, visto que a estrutura do Arco pode auxiliar os docentes em relação ao momento de planejar a implementação de aulas apoiadas nas TDIC, ou até mesmo como uso de metodologia de pesquisa para a área.

\section{O Arco de Maguerez}

O Arco de Maguerez foi constituído com base na Metodologia de Problematização, a mesma foi elaborada na década de 70 do século $\mathrm{XX}$, projetada inicialmente por Bordenave e Pereira (1982), e tem-se revelado como uma estratégia diferenciada na área da educação. Essa metodologia vem sendo explorada na Universidade Estadual de 
Londrina (UEL), desde 1992 em uma aproximação histórica-crítica da educação (COLOMBO; BERBEL, 1996).

O estudo para esta Metodologia de Problematização (MP) emergiu da necessidade de uma perspectiva de ensino voltada a construção de conhecimento pelo aluno. $\mathrm{Na}$ época foi pouco utilizada pela área da educação. Por muito tempo o material publicado por Bordenave e Pereira em 1982, foi o único disponível nos meios acadêmicos sobre o Arco de Maguerez, aplicado como caminho de Educação Problematizadora, inspirada em Paulo Freire (BERBEL, 2012).

Os autores utilizaram-se de um esquema elaborado por Charles Maguerez que foi denominado de Arco de Maguerez. Este modelo considera para a educação a realidade em que o indivíduo está inserida, suas vivências, suas experiências, seus saberes e conhecimento. Tem como principal objetivo o desenvolvimento cognitivo crítico, reflexivo e autônomo do educador e do educando. Este modelo pode ser aliado ao docente em momentos de formação educacional (BORDENAVE; PEREIRA, 2004).

Academicamente, o uso do Arco torna-se uma ferramenta enriquecedora, pois pode ser utilizado enquanto método de ensino e pesquisa, assim como para o desenvolvimento de projetos de extensão e orientação de trabalhos de conclusão de curso (BERBEL, 1995; 1996; 1998a,1998b; 1999; 2001; 2012).

O Arco de Maguerez desenvolve-se orientado em cinco etapas. Segundo Bordenave e Pereira (1989), é preciso seguir alguns passos:

Observação da realidade (levantamento do problema); b) pontos chaves (reflete a respeito do problema); c) teorização; d) hipótese de solução (argumenta as hipóteses elaboradas); e) aplicação à realidade (prática) (BORDENAVE; PEREIRA, 1982, p. 83).

De acordo com autores Bordenave e Pereira (1989), a estrutura do Arco de Maguerez tende a proporcionar integração da teoria à prática, e contribui para que o aluno construa o conhecimento com a observação de problemas reais e com desafios de criar soluções originais e criativas.

\section{Metodologia}

Este trabalho caracteriza-se como abordagem metodológica com a perspectiva qualitativa de natureza descritiva. As abordagens de Ludkëe André (1986), Bordenave e Pereira (2004), Lakatos e Marconi (2010), dão as diretrizes para este trabalho.

O público-alvo desta pesquisa foram 25 alunos na disciplina de Metodologia do Ensino Mediada por Tecnologias da Informação e Comunicação matriculados no Programa Especial de Graduação (PEG) da Universidade Federal de Santa Maria. O Programa Especial de Graduação para a Educação Profissional permite a atuação do profissional nas disciplinas curriculares de sua área técnica, em espaços educacionais ou não, com adultos e jovens que se encontrem matriculados na educação básica ou superior (UFSM, 2015).

Para estes alunos foi oferecido uma oficina de capacitação intitulado: O uso pedagógico de Podcast, com duração de 30 horas o qual realizou-se em uns dos laboratórios de informática do Centro de Educação (CE) da UFSM. A oficina pedagógica teve a intenção de apresentar aos envolvidos, futuros profissionais que irão atuar na Educação Profissional e Tecnológica (EPT), uma diferente Tecnologia Digital de Informação e Comunicação para que assim, possam empregar em suas aulas o uso do Podcast como uma ferramenta digital educacional. 
O desenvolvimento deste trabalho seguiu o planejamento estruturado através do Arco de Maguerez como demonstra a Figura 1 a seguir:

Figura 1- Modelo da estrutura do Arco de Maguerez.

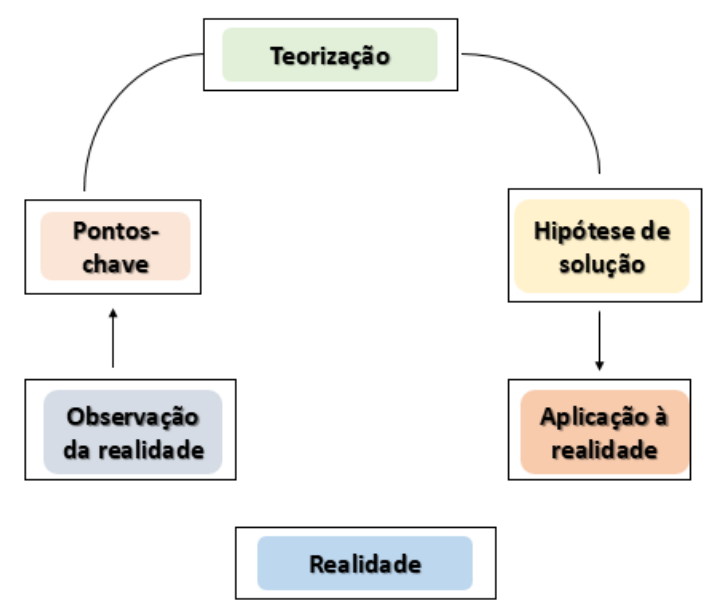

Fonte: BERBEL (2012)

Cada um dos passos do Arco são essenciais e possuem uma função no desenvolvimento do trabalho. O Arco de Maguerez auxiliou por meio de sua estrutura metodológica a implementação da oficina, possibilitando a organização das partes e assim favorecendo à compreensão objetiva e clara do que se pretendia em cada etapa. Uma vez que temos a estrutura do Arco pronta, basta incluir a temática nesta estratégia e seguir a ordem proposta. A seguir detalharemos o processo do uso do arco como estruturador pedagógico.

\section{Aplicação do Arco de Maguerez para uma Oficina Pedagógica de Podcast}

\section{Observação da Realidade}

$\mathrm{Na}$ etapa da observação da realidade, a primeira atividade, elaborada foi a identificação do público-alvo a ser implementado na pesquisa. Para tal foi escolhido os alunos matriculados na disciplina Metodologia do Ensino Mediada por Tecnologias da Informação e Comunicação, do PEG, por se tratar de futuros professores, da EPT que estão em busca da formação pedagógica para a docência no âmbito do Ensino Básico, Técnico e Tecnológico (EBTT).

Para essa etapa (observação da realidade), pode-se usar diversas estratégias como visitas técnicas, filmes, dramatização, reportagens/notícias, discussão em grupo, entrevistas com população e especialistas, dentre outras, as quais permitam aos alunos uma aproximação da realidade (BORDENAVE; PEREIRA, 2004). Assim, no primeiro encontro presencial, fez-se uma reflexão sobre a forma como as tecnologias digitais educacionais estão inseridas no contexto educacional, como é para estes alunos apresentada as TDIC durante o semestre letivo e que tecnologias digitais são exploradas por eles.

Ao serem questionados, os alunos apontam que o uso de TDIC é comum no seu cotidiano, tendo como o principal objetivo: o lazer (100\%), seguido de suporte informacional $(80 \%)$ e apoio didático $(65 \%)$. Adicionalmente, $70 \%$ dos alunos admitem que passam acima de três horas por dia conectados, e neste tempo de uso, a maior parte é destinado ao uso em Redes Sociais (100\%), assistindo a vídeos, filmes ou 
documentários (85\%) ou analisando seus e-mails (75\%). Prevendo que boa parte dos nossos participantes buscam manter-se informados, questionamos sobre qual mídia utilizam para tal. Obtivemos a Internet (100\%) como principal fonte de informação e atualização em tempo real, enquanto o jornal televisivo (80\%), surge como uma segunda opção para nossos alunos. Quando perguntado sobre o uso de TDIC pedagogicamente, os alunos afirmam utilizar a Internet em suas pesquisas, $77 \%$ avaliam ser imprescindível o uso de recursos tecnológicos para seus estudos e ainda, admitem que a ferramenta mais utilizada para apresentação de trabalhos e pesquisas têm sido o Power Point.

\section{Pontos chave}

A seguir, foram elencados os pontos chave da pesquisa, com a intenção de demarcar a investigação e dar início a reflexão acerca das possíveis causa do problema. Esse é um momento de síntese, onde após a seleção delimitar o que será estudado sobre o problema, elenca-se os tópicos que necessitam de atenção para conhecimento e reflexão, a fim de que se obtenha uma resposta ao problema (BERBEL, 1998). No nosso caso o problema era o uso pedagógico das TDIC.

Assim, ao observar à realidade foi possível verificar que apesar dos alunos estarem matriculados na disciplina Metodologia do Ensino Mediada por Tecnologias da Informação e Comunicação, que estuda o uso de tecnologias digitais relacionadas à educação, ela em sua maioria é abordada teoricamente com as mesmas ferramentas já conhecida por eles. Deste modo, para elencarmos os pontos chave da pesquisa fizemos os seguintes questionamentos apresentados na Figura 2.

Figura 2- Questionamentos para apontar os pontos chave

\begin{tabular}{|c|c|c|}
\hline $\begin{array}{l}\text { Os alunos possuem } \\
\text { fluência pedagógica } \\
\text { para a escolha de } \\
\text { recursos } \\
\text { educacionais } \\
\text { digitais? }\end{array}$ & $\begin{array}{c}\text { Os alunos já } \\
\text { produziram ou } \\
\text { adaptaram materiais } \\
\text { digitais para uso no } \\
\text { contexto } \\
\text { educacional? }\end{array}$ & $\begin{array}{c}\text { Os alunos fazem uso } \\
\text { de podcast para seu } \\
\text { aprendizado? }\end{array}$ \\
\hline
\end{tabular}

Fonte: as autoras

Com isso, os alunos foram questionados sobre o recurso Podcast. Interessante foi percebemos que em suas respostas, alguns alunos admitem fazerem o uso de Podcast (5\%), no entanto ao serem indagados acerca do Podcast como ferramenta educacional, os mesmos afirmam desconhecer o recurso digital.

Logo, analisamos e refletimos a possibilidade de ser apresentada uma diferente ferramenta educacional aos alunos, o Podcast e que está aula tivesse sua parte prática para que a turma conseguisse manusear o software, e de fato produzir seus próprios recursos educacionais.

\section{Teorização}

A teorização inicia-se na busca de informações, no intuito de compreender os fatores que envolvem o problema. Porque os alunos não estavam indo para os laboratórios de informática conhecer, ou manusear diferentes ferramentas educacionais? Aquelas aulas teóricas eram suficientes? E como se davam estas aulas? Com ajuda de algum recurso tecnológico? Estes e outros questionamentos foram sendo elencados. 
Durante a aplicação do Arco surgiram questionamentos após o relato dos alunos, decorrentes do processo de reflexão do grupo, a saber: As aulas que foram propostas utilizavam corretamente as TDIC?; Pode ser aplicada a TDIC em um curso apenas de forma teórica? Como as tecnologias são escolhidas pelos professores?

A terceira etapa do Arco Maguerez (Teorização), é o ponto em que os alunos passam a notar o problema e questionar o porquê das situações observados nas fases anteriores. Uma teorização bem-sucedida encaminha o sujeito a entender o problema, não apenas em suas experiências, mas também os princípios teóricos que os explicam. Nesse momento de teorização acontecem as operações mentais que favorecem o crescimento intelectual dos alunos. Todos os envolvidos no processo devem estudar o assunto (BORDENAVE; PEREIRA, 2004).

Segue o processo de coleta de dados com a ajuda de instrumentos de pesquisa e busca de fundamentação teórica. Assim, preparamos os instrumentos de coleta de informação (pesquisa em referenciais teóricos - identificação do contexto por meio de questionários). Para suprir nossos questionamentos da etapa da observação da realidade e demais momentos precisamos de respostas dos participantes, realizamos questionários. Analisamos as informações e concluímos a função do problema logo após registramos toda teorização.

Com base nas discussões em sala de aula e do questionário inicial aplicado, pode-se inferir sobre alguns aspectos como em relação às ferramentas tecnológicas oferecidas no curso e o tipo de materiais didáticos disponibilizados pelos docentes. Os resultados nos permitem afirmar, como podemos observar na Figura 3, que a maior parte dos professores usam em suas aulas os recursos audiovisuais como Data Show e Vídeos. Uma pequena parte faz uso de Ambientes Virtuais de Aprendizagens; destacamos que o Podcast, portfólios não tinha ainda sido utilizado por nenhum professor, enquanto que uma pequena parcela já fez uso de jogos didáticos.

Figura 3- Representação gráfica quanto a forma em que os professores utilizam a Internet com os alunos e resultados do questionário em relação aos materiais didáticos mais utilizados no curso.
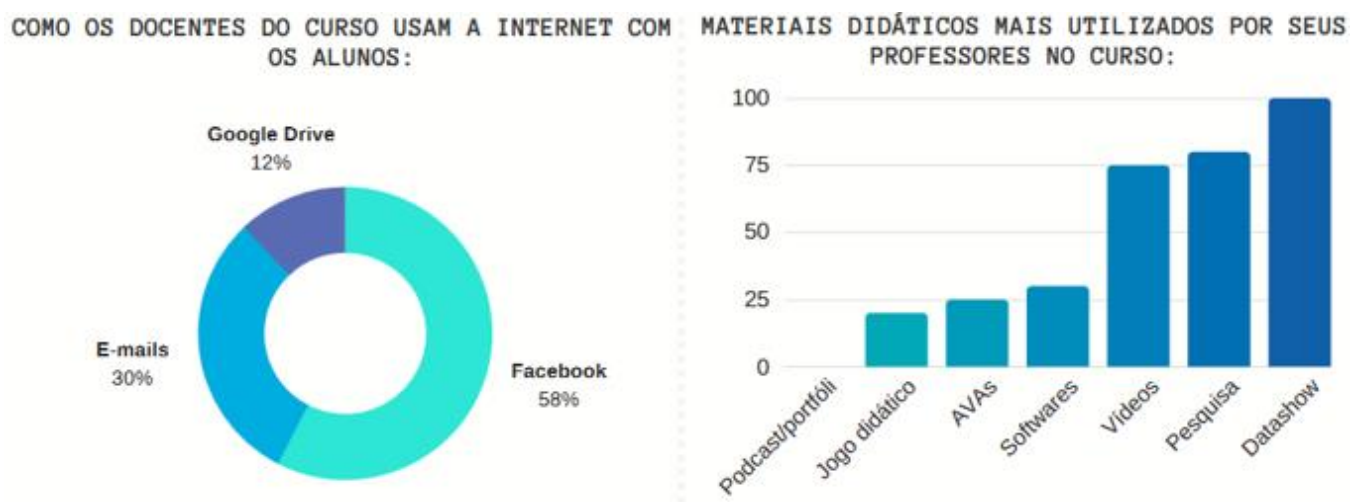

Fonte: as autoras

Podemos também identificar, que os professores fazem uso da Internet com os seus alunos, através de comunicação via e-mail, Redes Sociais, neste caso foi citado o Facebook e Google Drive. Isso expressa que os docentes do curso se demonstram preocupados com a integração dos recursos tecnológicos como forma de estruturar novos espaço de ensinar e aprender. No entanto há ainda muito trabalho a ser feito no que se refere à inserção das TDIC neste cenário. 


\section{Hipóteses de solução}

Ao tratar da Hipótese de solução é estruturada uma possibilidade para mudança na realidade do problema, que será estabelecida na pesquisa, na última etapa, aplicação à realidade, será ofertada para modificação do todo ou de uma parcela da realidade de onde se extraiu o problema, mediante às hipóteses de solução elaboradas.

Deste modo, elaboramos as hipóteses de soluções para o problema, como ofertar aos alunos uma oficina pedagógica de Podcast. Compreendemos esta como a forma que melhor se adapta para apresentar a ferramenta educacional para estes alunos.

Ressaltamos que tínhamos em mente uma possibilidade tecnológica, o Podcast, mas a análise que fizemos serviu para obtermos um panorama de quantas outras tecnologias poderiam ser oferecidas a estes alunos, ou ainda focar em outras questões que envolvem as TDIC.

\section{Aplicação a Realidade}

Por fim, planejamos as execuções de ações pelas quais promete que foi analisar a Aplicabilidade da ferramenta com os alunos, constando se o Podcast pode ser ou não uma boa ferramenta digital, colocamos em prática e registramos todo o processo, analisando os resultados. Antes disso, foi pensada a etapa prática em que os alunos iriam construir seus Podcasts, até como se daria a apresentação dos materiais produzidos pelos alunos.

Optamos por utilizar o site de repositório áudio digital o Podmatic, onde cada grupo fez seu cadastro e inseriu seu Podcast para que todos tivessem acesso aos arquivos. Após a apresentação dos Podcasts foi feita a análise final. Diante das respostas dos questionários ficou nítido que os alunos gostaram da experiência de produzir seus Podcasts, de conhecer uma nova ferramenta, porém, admitem se sentirem intimidados com o fato de terem que gravar suas falas.

Lançamos aos alunos duas afirmativas para que avaliassem de acordo com sua relação com o Podcast: "Gostei de produzir um Podcast" e "Considero fácil a produção de um Podcast"; na primeira afirmativa obtivemos 83\% dos alunos admitindo concordar totalmente com a frase, enquanto que para a segunda opção, apenas $17 \%$ admitem concordar totalmente com a afirmação, seguido de $39 \%$ que concordam e $33 \%$ que dizem não concordar nem discordar.

Aqui destacamos algumas dificuldades que surgiram nas falas dos alunos tais como: a pouca familiaridade com o microfone; por questões de timidez, entonação da voz; dificuldade ao ter que limitar o tempo adequado para o tipo de Podcast que escolheram, e ainda incerteza quanto ao tipo de conteúdo didático que melhor se adaptaria, para transformar em um Podcast. Ao contrário de todos os exemplos mencionados, alguns alunos afirmam que não encontram motivos para não utilizar o Podcast. Estes resultados descreveram sua resposta admitindo:

“Pretendo utilizar sim o Podcasts em minhas aulas. ” (Aluno 13).

“Não vejo esses fatores como desculpa para não usar o Podcast. ” (Aluno 18).

Constatou-se também que escolheriam o Podcast para ser usado em suas aulas dependendo do conteúdo de forma informativa/expositiva, ou seja, usar a ferramenta com a finalidade de levar informações pertinentes a turma, conteúdos, avaliações, planejamentos entre outros e expondo temáticas de conteúdo. Perguntamos ainda que fator poderia ser motivacional para que eles fizessem o uso constante do Podcast em sua prática docente: $26 \%$ assumem que relatos bem-sucedidos dos seus colegas, a alta 
aplicabilidade do recurso educacional didático e a questão de ter tempo disponível para produzir seus materiais neste formato são fatores que o motivariam a adotar os Podcasts para suas aulas. Enquanto que, $19 \%$ declaram que obter mais informações sobre a ferramenta poderia ser mais motivacional. Para $6 \%$ dos alunos a remuneração à parte para desenvolver materiais nesse formato seria motivador entre outros citados.

Em suma chegou-se então a identificação de algumas reflexões da pesquisa sendo elas: os alunos gostaram de conhecer o Podcast, e poder produzir o seu recurso educacional, aprendendo a como editar. Porém, percebe-se a necessidade de mais tempo de na oficina pedagógica, para familiarizar-se com a ferramenta. Tornar-se autor de seu material didático pode contribuir para à performance docente, à medida que conduz $\mathrm{o}$ autor às indagações como o que ensinar? Como ensinar? à quem ensinar?. Esse processo constitui-se do que denomina-se transposição didática.

Alguns alunos sentem-se inseguros para produzir seus recursos educacionais, isto pode ser pela falta de fluência no Audacity. Ou seja, em uma próxima possibilidade deveremos considerar mais tempo com a oficina para uso do Podcast. Os participantes reconhecem as vantagens que a ferramenta digital pode proporcionar ao contexto educacional, por ser rico em linguagens e abranger alunos com diferentes estilos de aprendizagem. Admitem, que à ferramenta pode dinamizar suas aulas e ser um diferencial, sendo que muitos mencionaram que utilizarão em sua práxis.

\section{Considerações Finais}

Este trabalho evidenciou o uso da estrutura do Arco de Maguerez em meio a implementação de uma oficina de capacitação que utilizou Tecnologias Digitais de Informação e Comunicação. $O$ caminho possibilitou perceber que a estrutura organizacional do Arco de Maguerez, com suas etapas, auxilia os momentos de planejamentos, com uso de tecnologias digitais pois, faz o docente refletir cada ação que será realizada juntamente com a consequência do que se propõem.

À metodologia do Arco de Maguerez, é enriquecedora por favorecer o olhar do docente/pesquisador, antes e depois da aplicação. Assim, pode-se fazer um panorama dos resultados sejam eles qualitativos ou quantitativos. Ademais ao final, à metodologia favorece à proposição de possíveis soluções para o problema (intenção principal).

Durante a aplicação do Arco Maguerez, percebemos que esta experiência instigou a curiosidade e a manutenção do interesse, dos alunos do PEG, no alcance dos objetivos do processo de ensino, sendo que sua proposta neste trabalho foi um sucesso. Conseguimos seguir as etapas e ao final termos um resultado gratificante. Os alunos tiveram a oficina de capacitação do uso pedagógico de Podcast, com sua parte teórica e prática, assim puderam conhecer mais uma tecnologia digital, que pode auxiliar na produção de atividades complementares, potencialmente acessíveis em diferentes espaços e lugares.

A pesquisa também serviu para que pudéssemos observar a maneira em que os alunos do PEG relacionam-se com uma diferente tecnologia digital o Podcast. Compreender que é uma possibilidade a ser utilizada futuramente em sua prática educacional. Alguns destes pontos foram sendo ilustrados através das respostas obtidas dos questionários elaborados na etapa de Teorização do Arco de Maguerez. Podemos refletir com os alunos o quanto é importante estarmos nos atualizando e levar isso aos professores, coordenadores e cursos. Acreditamos que este trabalho pode ser útil na área, uma vez que seu alcance é abrangente, podendo satisfazer como método de ensino e pesquisa, ou ainda no desenvolvimento de projetos de extensão e orientação de trabalhos de conclusão de curso 


\section{Referências}

BERBEL N. A. N.: A metodologia da problematização com o Arco de Maguerez: uma reflexão teórico-epistemológica. Londrina: EDUEL, 2012. 204p.

:A problematização e a aprendizagem baseada em problemas: diferentes termos ou diferentes caminhos? Interface: comunic, saúde, educ.]. 1998 fev; <Disponível em: http://www.scielo.br/scielo.> Acesso em Mar. 2018.

BERBEL, N. A. N.: (Org.): Metodologia da Problematização: uma alternativa metodológica apropriada para o ensino superior. SEMINA: Ci, Soc./Hum, Londrina, v. 16, n.2, Ed. Especial, p. 9-19, out. 1995.

,Metodologia da Problematização no Ensino Superior e sua contribuição para o plano da praxis. Semina: v.17, n. esp., p.7-17, 1996

,Metodologia da problematização: experiências com questões de ensino superior. Londrina: EDUEL, 282p.1998a.

,Metodologia da problematização: experiências com questões de ensino superior, ensino médio e clínica. Londrina: EDUEL, 251p.1998b.

,Metodologia da Problematização: fundamentos e aplicações. Londrina: Editora UEL, 1999.

Conhecer e intervir: o desafio da metodologia da problematização. Londrina: EDUEL, 2001

COlOmbO, A. A.; BERBEL, N. A. N. A Metodologia da Problematização com o Arco de Maguerez e sua relação com os saberes de professores. In: Seminário: Ciências Sociais e Humanas, Londrina, v. 28, n. 2, p. 124, jul./dez. 2007.

COLL, C. Aprender y enseñar con las TIC: expectativas, realidad y potencialidades. In CARNEIRO, R.; TOSCANO, J. C.; DÍAZ, T. Los desafíos de las TIC para el cambio educativo. Madrid, España: Fundación Santillana, 2009.

DIAZ BORDENAVE, J.; PEREIRA, A. Martins. In: MINISTÉRIO DA SAÚDE, Secretaria da Geral. Secretaria de Modernização Administrativa de Recursos Humanos. Brasília, p.19-26. 1989.

,Estratégias de ensino-aprendizagem. 25a ed. Petrópolis, RJ: Vozes; 2004.

KENSKI, V. Educação e tecnologias: O novo ritmo da informação. 3. ed. Campinas, SP: Papirus, 2012.

LÜDKE, M.; ANDRÉ, M. E. A. Pesquisa em educação: abordagens qualitativas. São Paulo: EPU, 1986.

MORAN, J. M. Ensino e aprendizagem inovadores com tecnologias audiovisuais e telemáticas. In: MORAN, J. M.; MASETTO, M. T.; BEHRENS, M. A. Novas Tecnologias e mediação Pedagógica. Ed 21 ${ }^{\mathrm{a}}$. Campinas: Papirus, 2013. 
Educação Híbrida. In: BACICH, L.; N, A. T.; TREVISANI, F.M (Orgs.). Ensino Híbrido: personalização e tecnologia na educação. Porto Alegre: Penso, 2015. 2, 2015 .

SANCHO, J. M.; HERNANDEZ, F. et. al. (Org): Tecnologias para transformar a educação. Porto Alegre: Artmed, 2006.

SOARES, A. B: O uso Pedagógico de Podcast na Educação Profissional e Tecnológica. Dissertação de Mestrado - Universidade de Santa Maria. Santa Maria Rio Grande do Sul. Programa de Pós-Graduação Em Educação Profissional e Tecnológica. 156p. 2017.

UFSM, Projeto Pedagógico do Curso. Disponível em http://w3.ufxx.br/peg/index.php?option=com_content\&view=article\&id=60\&Itemid=75 Acesso em Fev. de 2018. 